\title{
Effects of Collagen Membrane on Bone Level and Periodontal Status of Adjacent Tooth After Third Molar Surgery: a Randomised Controlled Trial
}

\section{Adnan Kilinc}

Ataturk University

Mert Ataol ( $\square$ ataolmert@gmail.com )

Private Clinic

\section{Research Article}

Keywords: Bone Level,Periodontal Status, Collagen Membrane, Healing Type, Partially Impacted Third Molar

Posted Date: October 25th, 2021

DOI: https://doi.org/10.21203/rs.3.rs-966880/v1

License: (c) (i) This work is licensed under a Creative Commons Attribution 4.0 International License. Read Full License 


\section{Abstract}

Background; After the surgical extraction of an impacted lower third molar, periodontal status and distal bone level of the adjacent second molar could be affected negatively. Healing type has been effected periodontal status and distal bone level of the adjacent second molar after third molar surgery.

Absorbable materials have some benefits including promoting wound healing through isolation, clot and wound stabilisation, and haemostasis; enhancing primary wound coverage. The aim of this study was to compare primary and secondary healing and collagen-membrane-based primary healing after surgical removal of partially erupted impacted third molars (3Ms), evaluating the distal alveolar bone level (ABL) and periodontal status of the adjacent second molars (2Ms).

Methods; Patients who met the inclusion criteria were randomised into three groups: secondary healing $(n=28)$, primary healing $(n=27)$ and membrane-based primary healing $(n=29)$. Digital panoramic radiographs were obtained preoperatively ( $\mathrm{T} 1$ ) and three months postoperatively (T2). The distances between the cemento-enamel junctions and the alveolar bone crests on the distal aspects of the adjacent $2 \mathrm{Ms}$ were measured using calibrated radiograph measurement software. The pocket depth and plaque index measurements were performed preoperatively and three months postoperatively. The periodontal plaque index (PPI) scores were registered on the distal aspects of the $2 \mathrm{Ms}$, and the mean values were used.

Results; Three of the applied healing types positively affected periodontal pocket depth (PPD) and periodontal index values $(p<0.05)$. In terms of the $A B L$ of the adjacent $2 M s$, primary $3-4 N /$ healing $(p=0.001)$ and membrane-based primary healing $(p=0.000)$ had superior results to secondary healing.

Conclusion; Membrane usage is promising for the distal bone gain and periodontal status of the adjacent $2 \mathrm{M}$.

Trial registration: This clinical study was registered started at 17/09/2018 by Australian New Zealand Clinical Trials Registry with the trial number of ACTRN12618001551280 .

\section{Background}

A serious condition that can arise after the surgical extraction of an impacted lower third molar (3M) is the deterioration of the periodontal status of the adjacent second molar (2M). This condition can take a chronic course that affects the long-term stability and survival of this tooth. It is a controversial but predominant opinion that bone loss on the distal aspect of the $2 \mathrm{Ms}$ may occur. In such cases, the cementum of the $2 \mathrm{M}$ can be exposed, and the condition may even require tooth extraction. ${ }^{[1,2]}$

Many researchers have focused on factors such as flap design, ${ }^{[3,4]}$ sutures, ${ }^{[5]}$ healing type, ${ }^{[6]}$ and adjunctive periodontal regenerative therapy ${ }^{[7,8]}$ for minimising this complication. However, it is still not clear whether primary or secondary intention healing can influence the distal bone level and periodontal status of the adjacent $2 \mathrm{Ms}$. In our literature search, the studies concerning healing type and bone level 
were not radiological but were clinical studies in which measurements were made using periodontal probes or periodontal index. ${ }^{[5,6,9,10]}$ Therefore, there was a need for a study evaluating distal bone level radiologically with clinical measurements.

Healing type has been suggested to periodontal status of the $2 \mathrm{Ms}$. When it concerns partially erupted impacted molars, primary intention healing is only possible with a sliding flap, and this would be difficult compared to fully impacted teeth without tissue loss. In these situations, primary wound healing could be supported with various materials. ${ }^{[6]}$

Absorbable materials have some benefits including promoting wound healing through isolation, clot and wound stabilisation, and haemostasis; enhancing primary wound coverage. ${ }^{[11]}$ Absorbable collagen membranes have been used in both the medical and dental fields for decades. To our knowledge, no previous study has been published evaluating the long-term effects of collagen membranes on distal bone regeneration and the periodontal tissues of adjacent $2 \mathrm{Ms}$ after the surgical removal of partially erupted impacted 3Ms.

This study intended to answer the following hypothesis: Is the administration of collagen membrane after surgical removal of partially erupted impacted $3 \mathrm{Ms}$ effective on periodontal healing? This study compared primary and secondary healing and collagen-membrane-based primary healing after surgical removal of partially erupted impacted $3 \mathrm{Ms}$, evaluating the distal alveolar bone level $(A B L)$ and periodontal status of the adjacent $2 \mathrm{Ms}$. The short-term results of this study were presented in a previous study.

\section{Methods}

This prospective, randomised controlled study included patients with vertical or mesioangular partially impacted 3Ms between 01/2017-09/2017 and the last data collected to 12/2017. Patients were excluded if they have medical illness or medication that could influence the course of postoperative wound healing. This clinical study was registered by Australian New Zealand Clinical Trials Registry with the trial number of ACTRN12618001551280. Patients between the ages of 18 and 30 were included. Patients were excluded from randomisation if they had acute pericoronitis, a pre-existing abscess or cellulitis, any restorations or carious lesions on the distal surfaces of the $2 \mathrm{Ms}$, or pathological conditions associated with the 3Ms.Oral contraceptive users and smokers were also excluded.

Patients were randomised to three groups by the envelope method: the secondary closure (SC) group, includes partial closure of the extraction site to provide secondary healing; the primary closure (PC) group, includes sliding the flap and suturing primarily to total closure of the extraction site; and the membrane-based primary closure (MBPC) group, includes placing a collagen membrane and sliding the flap to total closure of the extraction site.

Surgical operations were carried out by a single surgeon with each patient under local anesthesia, which was achieved with up to $4 \mathrm{~mL}$ of Articaine- $\mathrm{HCl}$ and a 1:100,000 ratio of epinephrine (Ultracaine D-S Forte, 
Aventis). An incision was made from the anterior border of the mandibular ramus, extending to the distal surface and the buccal gingivodental sulcus of the $2 \mathrm{M}$. The incision was continuous, with vertical incision, oblique into the mandibular vestibular fornix, aligned with the mesiobuccal cusp of the $2 \mathrm{M}$. A full-thickness mucoperiosteal triangular flap was elevated. If necessary, osteotomy was performed under constant irrigation.

The wound closure was performed with atraumatic silk sutures depending on the groups.In the SC group, the flap was positioned to its former position by a single suture distal to the $2 \mathrm{M}$, with leaving a gap. If necessary, a wedge of mucosa was removed. In the PC group, the sliding flap was sutured. In the MBPC group, the extraction socket was closed with a resorbable collagen membrane (Evolution®, OsteobiolTecnoss, Italy), and the sliding flap was sutured primarily.

The patients were given standard postoperative medication; antibiotics (amoxicillin + clavulanic acid), nonsteroidal anti-inflammatory drugs (dexketoprofen trometamol) and mouthwash (with $0.12 \%$ chlorhexidine). The sutures were removed after 7 days.

Parameters determined in this study included gender, duration of surgery, surgical difficulty, and the position of the $3 \mathrm{Ms}$. Surgical difficulty was recorded immediately after the procedure and evaluated using a four-class difficulty scale, as follows: 1 ,extraction requiring forceps only; 2 , extraction requiring osteotomy; 3 , extraction requiring osteotomy and coronal sectioning; and 4, complex extraction(root

sectioning ${ }^{[12]}$.The level of impaction of the 3 Mswas classified as being either on the level of the occlusal plane or between the occlusal plane and the cervical line of the $2 \mathrm{M}$ (below the occlusal plane), according to Pell and Gregory's classification. 3M angulation was classified on a two-class scale according to Winter's classification, being either 1, mesioangularor2, vertical. Digital panoramic radiographswas obtained to ensure the similarity of the impaction types according to angulation and relationship to the occlusal plane ${ }^{[13]}$.

\section{Periodontal Examination}

Another primary outcome variable was the periodontal status of the $2 \mathrm{Ms}$. Periodontal measurements were performed preoperatively (T1) and three months postoperatively (T2). The pocket depths and plaque index scores of the distobuccal (DB), distolingual (DL), midbuccal (MidB) and midlingual (MidL) surfaces of the $2 \mathrm{Ms}$ were recorded. All periodontal pocket depth (PPD)measurements were performed as millimeterusing William's periodontal probe (Aesculap AG\&Co., Tuttlingen, Germany).To assess the periodontal plaque index (PPI) scores, the Silness\&Löe plaque index was registered on the distal aspects of the $2 \mathrm{Ms}$, and the mean values were used.

\section{Radiographic Measurement}


Digital panoramic radiographs were obtained preoperatively andthree months postoperatively. Cementoenamel junction (CEJs) was used as reference points, and the distances between the CEJ and the alveolar bone crest on the distal aspect of the adjacent $2 \mathrm{Mweremeasured} \mathrm{as} \mathrm{millimetre} \mathrm{using} \mathrm{calibrated}$ radiograph measurement software (MedData Medical Software, Ankara, Turkey). All radiological measurements were performed twice and independently, and mean values were recorded preoperatively (T1) and three months postoperatively (T2). The differences (positive or negative) between the pre-and postoperative radiographic measurements constituted one of the primary outcomes of this study.

\section{Statistical Analysis}

The study data were subjected to power analysis to a posteriori check the acceptability of the sample size. The sample size was 30 participants per group (total=90) were analysed with an estimated error ( $(\mathrm{a})$ of 5 and $80 \%$ power, and the sample size was found to be appropriate $(0,69)$. Statistical analysis was performed using the SPSS statistical software package, version 20.0 (IBM, Chicago, IL, USA). The normalities of the distributions were tested using the Kolmogorov-Smirnov test. The Wilcoxon signed rank test was used for intragroup comparisons. For intergroup comparisons, the Kruskal-Wallis orchi-square tests was used, and for post hoc tests, the Bonferroni correction was used.

\section{Results}

Ninety patients were included in this study, but six of them quitted the study, and Eighty-four patients completed the study. The sample included 23 men (27.4\%) and 61 women (72.6\%), resulting in a male-tofemale ratio of 1:2.65. Table 1 compares the three groups based on factors that could have affected the outcome variables. These results show no statistically significant differences $(p>0.05)$ except in operation time $(\mathrm{p}=0.002)$ (Table 1$)$. 
Table 1

Study Variables and Descriptive Statistics

\begin{tabular}{|c|c|c|c|c|}
\hline & SC & PC & MBPC & \\
\hline & Mean or $\mathrm{n}$ & Mean or $n$ & Mean or $\mathbf{n}$ & (p) \\
\hline \multirow[t]{2}{*}{ Age (Std) } & 22.18 & 24.03 & 23.79 & \multirow[t]{2}{*}{0.196} \\
\hline & $(4.29)$ & $(4.49)$ & $(5.48)$ & \\
\hline \multicolumn{5}{|l|}{ Gender } \\
\hline Female & 21 & 20 & 20 & \multirow[t]{2}{*}{0.859} \\
\hline Male & 7 & 7 & 9 & \\
\hline Total & 28 & 27 & 29 & \\
\hline \multicolumn{5}{|l|}{ Angulation } \\
\hline Vertical & 20 & 16 & 22 & \multirow[t]{2}{*}{0.384} \\
\hline Mesioangular & 8 & 11 & 7 & \\
\hline \multicolumn{5}{|l|}{ Depth } \\
\hline Occlusal plane & 18 & 15 & 17 & \multirow[t]{2}{*}{0.799} \\
\hline Below occlusal plane & 10 & 12 & 12 & \\
\hline \multicolumn{5}{|l|}{ Surgical Difficulty } \\
\hline 1 & 15 & 13 & 14 & \multirow[t]{4}{*}{0.614} \\
\hline 2 & 5 & 5 & 7 & \\
\hline 3 & 6 & 5 & 2 & \\
\hline 4 & 2 & 4 & 6 & \\
\hline Operation Time & 10.89 & 15.15 & 15.86 & $0.002^{*}$ \\
\hline
\end{tabular}

The intragroup statistics,as well as the plaque index scores and probing depths taken preoperatively and three months postoperatively, are listed in Table 2. These results show that DB and DL pocket depths were reduced statistically significantly for all three groups $(p<0.05)$. MidB and MidL pocket depths were statistically significantly reduced in the MBPC group ( $p=0.000, p=0.012$, respectively), but not in the SC or PC group ( $p>0.05)$. Plaque index and oral health positively differed for all three groups $(p=0.000)$. There were no statistically significant differences among the groups according to intergroup comparisons of PPD and PPI ( $p>0.05)$. 
Table 2

Means, standard deviations and comparisons of periodontal measurements

\begin{tabular}{|c|c|c|c|c|c|c|c|c|c|c|}
\hline & SC & & & PC & & & MBPC & & & \\
\hline & T1 & T2 & \multirow[t]{3}{*}{$\mathrm{p}$} & T1 & $\mathrm{T} 2$ & \multirow[t]{3}{*}{$p$} & T1 & T2 & \multirow[t]{3}{*}{$\mathrm{p}$} & \multirow[t]{3}{*}{$p$} \\
\hline & Mean & Mean & & Mean & Mean & & Mean & Mean & & \\
\hline & $(\mathrm{Std})$ & $(\mathrm{Std})$ & & (Std) & (Std) & & $(\mathrm{Std})$ & $(\mathrm{Std})$ & & \\
\hline \multirow[t]{2}{*}{ DB } & \multirow{2}{*}{$\begin{array}{l}3.57 \\
(1.79)\end{array}$} & \multirow{2}{*}{$\begin{array}{l}2.29 \\
(0.67)\end{array}$} & \multirow[t]{2}{*}{$0.001^{*}$} & \multirow{2}{*}{$\begin{array}{l}4.11 \\
(1.78)\end{array}$} & 2.54 & \multirow[t]{2}{*}{$0.000^{*}$} & \multirow{2}{*}{$\begin{array}{l}3.86 \\
(1.46)\end{array}$} & \multirow{2}{*}{$\begin{array}{l}2.26 \\
(0.81)\end{array}$} & \multirow[t]{2}{*}{$0.000 *$} & \multirow[t]{2}{*}{0.531} \\
\hline & & & & & $(0.75)$ & & & & & \\
\hline DL & $\begin{array}{l}3.50 \\
(1.75)\end{array}$ & $\begin{array}{l}2.16 \\
(0.64)\end{array}$ & $0.000 *$ & $\begin{array}{l}4.19 \\
(1.86)\end{array}$ & $\begin{array}{l}2.41 \\
(1.01)\end{array}$ & $0.000 *$ & $\begin{array}{l}3.31 \\
(1.51)\end{array}$ & $\begin{array}{l}1.90 \\
(0.47)\end{array}$ & $0.000 *$ & 0.429 \\
\hline MidB & $\begin{array}{l}1.79 \\
(0.63)\end{array}$ & $\begin{array}{l}1.48 \\
(0.50)\end{array}$ & 0.056 & $\begin{array}{l}1.89 \\
(0.64)\end{array}$ & $\begin{array}{l}1.61 \\
(0.74)\end{array}$ & 0.070 & $\begin{array}{l}1.93 \\
(0.65)\end{array}$ & $\begin{array}{l}1.40 \\
(0.49)\end{array}$ & $0.000^{*}$ & 0.500 \\
\hline MidL & $\begin{array}{l}1.86 \\
(0.52)\end{array}$ & $\begin{array}{l}1.66 \\
(0.55)\end{array}$ & 0.065 & $\begin{array}{l}2.04 \\
(0.94)\end{array}$ & $\begin{array}{l}1.57 \\
(0.74)\end{array}$ & 0.081 & $\begin{array}{l}1.76 \\
(0.69)\end{array}$ & $\begin{array}{l}1.40 \\
(0.49)\end{array}$ & $0.012^{*}$ & 0.295 \\
\hline PPI & $\begin{array}{l}1.39 \\
(0.88)\end{array}$ & $\begin{array}{l}0.61 \\
(0 . \\
69)\end{array}$ & $0.000 *$ & $\begin{array}{l}1.52 \\
(0.85)\end{array}$ & $\begin{array}{l}0.56 \\
(0.64)\end{array}$ & $0.000 *$ & $\begin{array}{l}1.34 \\
(0.77)\end{array}$ & $\begin{array}{l}0.55 \\
(0.69)\end{array}$ & $0.000 *$ & 0.608 \\
\hline
\end{tabular}

Table 3 shows the height differences in the ABL for all groups as measured preoperatively and three months postoperatively in the radiographs at the $2 \mathrm{Ms}$ 'distal surfaces. These results show that there was no statistically significant difference in distal bone level in the SC group $(p=0.08)$.Controversially, there were statistically significant differences in the PC group $(p=0.01)$ and MBPC group $(p=0.000)$. In the intergroup comparison, there was a statistically significant difference among the three groups $(p=0.000)$.In binary comparisons, although the change in distal bone level scores was statistically significantly superior in the MBPC and PC groups to that in the SC group, there was no statistically significant difference between the PC and MBPC groups $(p=0.053)$. 
Table 3

Means, standard deviations and comparisons of alveolar bone level

\begin{tabular}{|llll|}
\hline & SC & PC & MBPC \\
\hline & Mean (Std) & Mean (Std) & Mean (Std) \\
\hline T1 & $2.36(1.31)$ & $3.13(1.95)$ & $2.86(1.41)$ \\
\hline T2 & $2.73(1.55)$ & $2.41(1.03)$ & $1.50(0.44)$ \\
\hline P & 0.088 & $0.01^{*}$ & $0.000^{*}$ \\
\hline T2-T1 & $-0.38(1.11)$ & $0.72(1.30)$ & $1.36(1.24)$ \\
\hline Intergroup comparison & Binary Comparisons & \\
\hline & SC/PC & SC/MBPC & PC/MBPC \\
\hline p & p & $\mathrm{p}$ & $\mathrm{P}$ \\
\hline 0.000 & $0.001^{*}$ & $0.000^{*}$ & 0.053 \\
\hline Std: Standard Deviation; ${ }^{*} \mathrm{p}<0.05 ;$ T1: Preoperatively; T2: Three Months Postoperatively \\
\hline
\end{tabular}

\section{Discussion}

The healing result of a single site is dependent on a number of factors at baseline that may vary from site to site or person to person ${ }^{[14]}$.For this reason, taking into account the randomised nature of this study, the inclusion criteria were rigorously planned and applied to make the groups comparable. There was no statistically significant difference among the groups in terms of age, gender, angulation, depth, and surgical difficulty ( $p>0.05)$. These results show that all three groups were comparable in terms of periodontal healing and bone level.

In studies comparing primary and secondary wound healing and investigating the effect of extracting partially impacted $3 \mathrm{Ms}$ on the periodontal health of $2 \mathrm{Ms}$, deep periodontal pockets have been reported. ${ }^{[2]}$ In contrast, other studies have reported a decrease in the PPD at the distal aspect of the $2 \mathrm{Ms}{ }^{\left[{ }^{[4}\right.}$

${ }^{9]}$ Referring to these results, the investigators reported that the periodontal problems in the soft tissues around the $2 \mathrm{Ms}$ after $3 \mathrm{M}$ surgery were not related to the flap technique and that this technique did not affect the periodontal health of the $2 \mathrm{Ms}{ }^{[15]}$ Also, PPD value has a linear relationship with the number of anaerobic organisms in the mouth and is associated with some factors including oral hygiene. ${ }^{[16,17]}$ For this reason, PPD values may not always correspond well with ABL values. ${ }^{[17]}$

Hashemi et al. ${ }^{[5]}$ and Korkmaz et al. ${ }^{[6]}$ showed that at their three-month follow-up, neither the primary nor secondary closure group showed a statistically significant difference between the preoperative and postoperative measurements of PPD around the 2Ms. In addition, they reported that PPD values were less 
than $3 \mathrm{~mm}$ in both groups. Cortell-Ballester et al. ${ }^{[7]}$ used resorbable collagen membranes during fully impacted mandibular $3 \mathrm{M}$ surgery and reported that it reduced the distal PPD of the adjacent $2 \mathrm{Ms}$. In the present study, statistically significant decreases in the DB and DLPPD and PPI were observed at the threemonth follow-up with all three healing approaches. However, there were no statistically significant differences among the groups in PPD and PLI $(\mathrm{p}<0.05)$.

On the other hand, the scientific data about dimensional bone changes occurring after $3 \mathrm{M}$ surgery distal to the adjacent 2 Mswas limited in the studies investigating primary and secondary wound healing.

In line with our findings, Aimetti et al. ${ }^{[18]}$ evaluated the effects of the placement of a membrane distal to the adjacent $2 \mathrm{Ms}$ after $3 \mathrm{M}$ surgery and reported statistically significant bone gain. Sammartino et al. ${ }^{[10]}$ showed successful results on bone level with the usage of a collagen membrane with platelet-rich plasma. Cortell-Ballester et al. ${ }^{[7]}$ conducted a study using absorbable collagen membrane and showed that its use had supported healing and increased bone formation at a three-month follow-up. In the present study, there was a statistically significant difference between the PC and SC groups and between the $S C$ and MBPC groups $(p<0.05)$. These results suggest that primary healing methods may be advantageous in terms of ABL. On the other hand there was a statistically non-significant positive result on bone level between the primary healing and membrane-based primary healing groups $(p=0.053)$, and these three-month follow-up results are seen as promising for bone gain on the distal aspects of adjacent $2 \mathrm{Ms}$.

\section{Conclusion}

According to this study, all three healing types applied in this study positively affected PPD and PPI values. This result may be related to the easier removal of plaque at the distal aspects of the $2 \mathrm{Ms}$ after extraction. On the other hand, in terms of the $\mathrm{ABL}$ of the $2 \mathrm{Ms}$, primary healing and membrane-based primary healing had superior results to secondary healing.In our opinion, especially when the patient's bone level is insufficient, primary healing is advantageous and preferable. Additionally, the use of resorbable collagen membranes is a promising approach after the surgical extraction of impacted lower $3 \mathrm{Ms}$, as it positively affects bone regeneration and improves the periodontal status of the adjacent $2 \mathrm{Ms}$.

\section{Abbreviations}

3M, third molar; 2M, second molar; ABL, alveolar bone level; , CEJ, cemento-enamel junction; DB, distobuccal; DL, distolingual; MBPC , membrane-based primary closure; MidB, midbuccal; MidL, midlingual; PC, primary closure; PPD, periodontal pocket depth; PPI, periodontal plaque index; SC, secondary closure; T1, preoperative time; T2, postoperative time.

\section{Declarations}

Ethical Approval and Consent to Participate 
This study followed the Declaration of Helsinki on medical protocol and ethics, the regional Ethical Review Board of the Ataturk University Faculty of Dentistry approved the study. A written informed consent was obtained from all individual participants or their parents or legal guardians.

\section{Consent to Publish}

The authors understand and agree that the material could be published in a journal, Web site or other form of publication.

\section{Availability of Data and Materials}

This clinical study was registered by and the data of this study could be reached at Australian New Zealand Clinical Trials Registry with the trial number of ACTRN12618001551280

\section{Competing Interest}

Dr. Kılınç declares that he has no conflicts of interest. Dr. Ataol declares that he has no conflicts of interest.

\section{Funding}

This study was supported in part by grants from the Scientific Research Project Fund of Ataturk University, Erzurum, Turkey. (BAP 2016/091). Additional support was provided by the Ataturk University Faculty of Dentistry. The funding bodies had no role in study design, collection, analysis, or interpretation of data; in the writing of the manuscript; or in the decision to submit the manuscript for publication.

\section{Authors' Contributions}

All authors contributed extensively to the work presented in this paper. AK designed the study and performed surgeries. MA performed the postoperative measurements. AK and MA searched the articles for the review. AK drafted and wrote the manuscript. All authors read and approved the final version of the manuscript.

\section{Acknowledgements}

Not Applicable 


\section{References}

1. Karaca I, Şimşek Ş, Uğar D, Bozkaya S. Review of flap design influence on the health of the periodontium after mandibular third molar surgery. Oral Surgery, Oral Med Oral Pathol Oral Radiol Endodontology 2007;104:18-23. doi:10.1016/j.tripleo.2006.11.049.

2. Peng K-Y, Tseng Y-C, Shen E-C, Chiu S-C, Fu E, Huang Y-W. Mandibular second molar periodontal status after third molar extraction. J Periodontol 2001;72:1647-51.

3. Yolcu Ü, Acar AH. Comparison of a new flap design with the routinely used triangular flap design in third molar surgery. Int J Oral Maxillofac Surg 2015:8-11. doi:10.1016/j.ijom.2015.07.007.

4. Kim H, Choi B. A Comparative Study on the Extractions of Partially Impacted Mandibular Third Molars With or Without a Buccal Flap: 2011:966-70. doi:10.1016/j.joms.2010.02.025.

5. Hashemi HM, Beshkar M, Aghajani R. The effect of sutureless wound closure on postoperative pain and swelling after impacted mandibular third molar surgery. Br J Oral Maxillofac Surg 2012;50:2568. doi:10.1016/j.bjoms.2011.04.075.

6. Korkmaz TY, Mollaoglu N, Ozmeriç N. Does Laterally Rotated Flap Design Influence the Short-Term Periodontal Status of Second Molars and Postoperative Discomfort Following Partially Impacted Third Molar Surgery? J Oral Maxillofac Surg 2015. doi:10.1016/j.joms.2015.01.005.

7. Cortell-Ballester I, Figueiredo R, Valmaseda-Castellón E, Gay-Escoda C. Effects of Collagen Resorbable Membrane Placement After the Surgical Extraction of Impacted Lower Third Molars. J Oral Maxillofac Surg 2015:1-8. doi:10.1016/j.joms.2015.02.015.

8. Zwahlen RA, Cheung LK, Zheng L-W, Chow RLK, Li T, Schuknecht B, et al. Comparison of two resorbable membrane systems in bone regeneration after removal of wisdom teeth: a randomizedcontrolled clinical pilot study. Clin Oral Implants Res 2009;20:1084-91. doi:10.1111/j.16000501.2009.01751.x.

9. Montero J, Mazzaglia G. Effect of Removing an Impacted Mandibular Third Molar on the Periodontal Status of the Mandibular Second Molar. YJOMS 2011;69:2691-7. doi:10.1016/j.joms.2011.06.205.

10. Sammartino G, Tia M, Gentile E, Marenzi G, Claudio PP. Platelet-rich plasma and resorbable membrane for prevention of periodontal defects after deeply impacted lower third molar extraction. $J$ Oral Maxillofac Surg 2009;67:2369-73. doi:10.1016/j.joms.2009.04.093.

11. Bunyaratavej P, Wang H. Collagen Membranes: A Review 2001:215-29.

12. Lago-Méndez L, Diniz-Freitas M, Senra-Rivera C, Gude-Sampedro F, Rey JMG, García-García A. Relationships between surgical difficulty and postoperative pain in lower third molar extractions. $J$ Oral Maxillofac Surg 2007;65:979-83.

13. Alvira-gonzález J, Figueiredo R, Valmaseda-castellón E, Quesada-gómez C. Predictive factors of difficulty in lower third molar extraction: A prospective cohort study 2017;22. doi:10.4317/medoral.21348.

14. Kugelberg CF. Periodontal. healing two and four years after mpacted lower third molar surgery. Int $J$ Oral Maxillofac Surg 1990;19:341-5. 
15. Aloy-Prósper A, Mira BG, Larrazabal-Morón C, Peñarrocha-Diago M. Distal probing depth and attachment level of lower second molars following surgical extraction of lower third molars: A literature ... doi:10.4317/medoral.15.e755.

16. Ambrosini P, Miller N. Clinical and microbiological evaluation of the effectiveness of the Nd: Yap laser for the initial treatment of adult periodontitis A randomized controlled study 2005:670-6. doi:10.1111/j.1600-051X.2005.00738.x.

17. Karapataki S, Hugoson a, Kugelberg CF. Healing following GTR treatment of bone defects distal to mandibular 2nd molars after surgical removal of impacted 3rd molars. J Clin Periodontol 2000;27:325-32.

18. Aimetti M, Pigella E, Romano F. Clinical and radiographic evaluation of the effects of guided tissue regeneration using resorbable membranes after extraction of impacted mandibular third molars. Int $\mathrm{J}$ Periodontics Restorative Dent 2007;27.

\section{Figures}

\section{Image not available with this version}

\section{Figure 1}

Radiographic images of a MBPC group patient.A: Preoperative; B: Three Months Postoperative

\section{Supplementary Files}

This is a list of supplementary files associated with this preprint. Click to download.

- TrialProtocol.docx

- consort2010checklist.pdf 